\title{
Sex-dependent diel vertical migration in northern krill Meganyctiphanes norvegica and its consequences for population dynamics
}

\author{
Geraint A. Tarling*
}

British Antarctic Survey, Natural Environment Research Council, High Cross, Madingley Rd, Cambridge CB3 0ET, UK

\begin{abstract}
The diel vertical migration (DVM) and population dynamics of northern krill were investigated in the Clyde Sea over several years using depth-discrete net-sampling and a moored $300 \mathrm{kHz}$ acoustic Doppler current profiler. Krill performed DVM throughout each year of sampling. The respective arrival and departure of the krill scattering layer to and from the upper layers occurred consistently $30 \mathrm{~min}$ after sunset and $30 \mathrm{~min}$ before sunrise. DVM of males and females was different, with females migrating closer to the surface at night than males of equivalent size. The sex ratio was initially 1:1 when juveniles matured into adults after their first winter, but the ratio became increasingly biased towards males as the season progressed such that, by October, the ratio was close to 3:1. A deterministic individual-based model, in which predation risk was a function of the light available to visual predators, showed that the bias could be accounted for by the difference in risk taken by males and females as a result of their DVMs. The same model also showed that, during summer, the difference in these DVMs resulted in females making a net energy gain that was $40 \%$ higher than that of males. The predicted net energy gain for females met the immediate energetic demand for egg production as well as providing a surplus that could offset any future decline in food availability. The model did not predict the observation that the decline in male numbers was greater than that of females over the winter. This may be a result of females being more able to cope with starvation through reabsorption of their lipid-rich ovaries. The greater demand for energy to fuel reproduction appeared to be driving females to undertake a riskier DVM than males. This drive is likely to be common to most euphausiid species.
\end{abstract}

KEY WORDS: Euphausiid $\cdot$ Behaviour $\cdot$ Sex ratio $\cdot$ Mortality $\cdot$ Predation $\cdot$ Zooplankton $\cdot$ Acoustic Doppler current profiler · DVM

\section{INTRODUCTION}

In most pelagic environments, both the concentration of food and the risk of predation are highest close to the surface. The attenuation of light with water depth means that phytoplankton can only grow, and visually based predators, such as fish, can only hunt effectively when in the illuminated upper layers. Therefore, a strategy that aims to maximise energy intake will also incur the greatest predation risk, and optimal fitness is achieved only when these costs and benefits are balanced so that total lifetime reproductive success is maximised (Houston et al. 1993). The greater energetic input often required for egg produc- tion in many marine invertebrates makes the cost of reproduction markedly different between males and females. As a result, the trade-off between energy acquisition and risk of predation is likely to be different between sexes. For pelagic organisms, this tradeoff will often be reflected in their respective diel vertical migration (DVM) profiles, in particular, the decision of when to migrate and to what depth.

Most species of euphausiid perform DVM, of which the majority exhibit the classic pattern of ascent towards the surface layers at dusk and descent to depth at dawn (Mauchline \& Fisher 1969). Meganyctiphanes norvegica is one of the most prolific migrators, capable of ascending over $700 \mathrm{~m}$ in an hour 
(Tarling et al. 1999a). Nicol (1984) and Tarling et al. (1999b) showed that the migration behaviour of this species is modified by spawning and moulting activity, but such behaviour accounts for less than $5 \%$ of its lifecycle and, in the case of moulting, affects both sexes in similar ways (Tarling et al. 1999b). Sexual differences in DVM outside of the brief periods of spawning and moulting has been little considered, yet the consequences in terms of relative mortality rates is likely to have a large influence on the population dynamics of this species.

Female and male Meganyctiphanes norvegica have different energetic requirements as a result of their respective costs of reproduction. During the reproductive season, which can last between 3 and 7 mo, females build up resources in the ovaries over several weeks. By the time the female is ready to spawn, it has amassed over 1000 eggs, with a combined lipid content of more than $3 \mathrm{mg}$ ash-free dry weight (Cuzin-Roudy 2000). In the Clyde Sea, Tarling \& Cuzin-Roudy (2003) have shown that a female can go through 7 such cycles in a single year. The energetic cost of male production is less known, but it is undoubtedly much smaller given the diminutive size of the spermatophores and the fact that a female needs to be copulated once every moult cycle, which lasts ca. 2 wk in temperate regions.
Females rarely have more than one attached spermatophore and are often less abundant than males in the population (Boysen \& Buchholz 1984, Tarling et al. 1999b), so it is unlikely that many spermatophores are released by males every moult cycle. Furthermore, the total lipid content of males can be as low as half that of females (Cuzin-Roudy et al. 1999).

The fact that females need more energy for reproduction than males means that they may need to take more risks. In a classic pelagic situation, increasing food intake would mean migrating closer to the surface and/or remaining there for longer, which increases the risk of being detected by visual predators. As a result, one would expect that the loss of females to predation to be greater than the loss of males, which would produce an increasing bias towards the number of males through the course of the year. Establishing a reliable record of sex ratio over time is often difficult in field populations since many are influenced by immigration and emigration as a result of advection. The population found in the Clyde Sea is relatively free from such influences since a shallow sill (the Grand Plateau) at its entrance isolates it (Fig. 1). The site, nevertheless, retains many oceanic features (Rippeth et al. 1995) and is therefore a good model system for examining phenomena that may be more widespread.

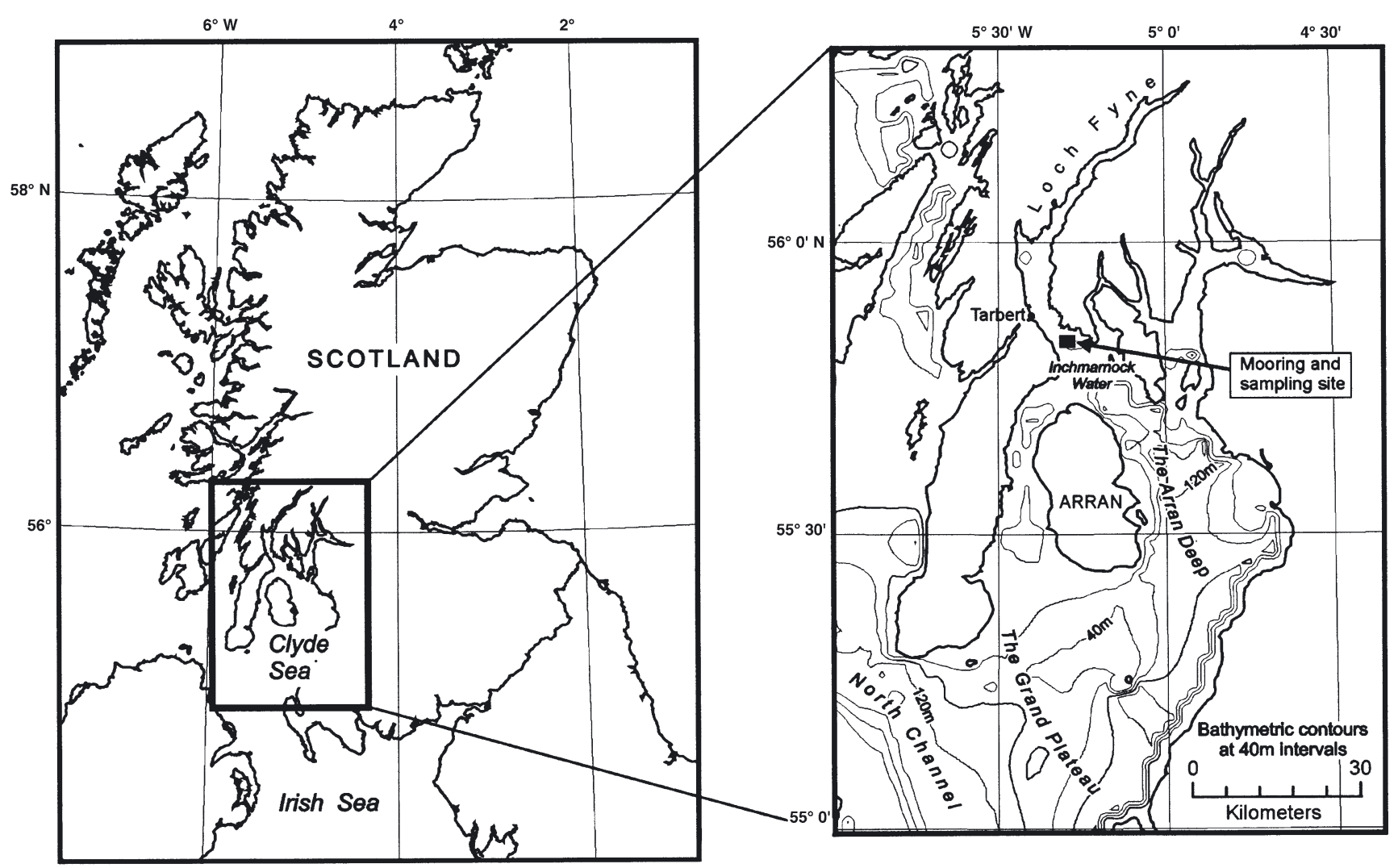

Fig. 1. The Clyde Sea, showing the site of the mooring and net-sampling 
In this study, net sampling and acoustics were used to determine, empirically, the behaviour and population dynamics of the population over an annual cycle. The costs and benefits of the DVM trajectories of each sex were assessed through the use of a previously published semi-empirical model (Tarling et al. 2000). The model was redesigned to compare the relative fate of males and females as a result of their observed DVMs. The model predicted the sex ratio over the course of a year, which was compared to observations testing the hypothesis that females trade-off their need for higher energy intake, by enduring a higher risk of mortality, compared with males.

\section{MATERIALS AND METHODS}

Overview. Empirical data from the Clyde Sea population of Meganyctiphanes norvegica were obtained from 2 separate campaign series. The first campaign series was carried out in July 1996 and March 1997, on board the oceanographic RV 'Heincke', from which sets of highly resolved net samples were obtained for the analysis of krill DVM. Physiological measurements of krill, and the determination of their trophic environment, were also carried out during this campaign series and published elsewhere (Tarling et al. 2000, Lass et al. 2001, Saborowski et al. 2002). In the second campaign series, continous information on krill migration was obtained with a moored acoustic Doppler current profiler (ADCP), deployed between June 1999 and July 2000. An inshore vessel (RV 'Calanus') visited the mooring site every other month during this period to catch krill for population dynamic analyses, and also to obtain temperature and light attenuation profiles. The surface light-regime was monitored continuously from a nearby land station. The physical, physiological and behavioural data from both campaign series were used in model parameterisation, while the population dynamics data from the second series were used to validate model predictions.

Field sampling. All sampling was carried out within a 140 to $160 \mathrm{~m}$-deep trench that runs along the length of the Clyde Sea (55.6 $6^{\circ}, 5.1^{\circ} \mathrm{W}$, Fig. 1). A $1 \mathrm{~m}^{2}$ MOCNESS (Wiebe et al. 1985) was deployed from the RV 'Heincke', equipped with 9 nets, a flowmeter, and temperature, salinity and depth sensors. Net 1 , with a $330 \mu \mathrm{m}$ mesh, was open during the descent of the net to within $15 \mathrm{~m}$ of the bottom. The other 8 nets, with $2 \mathrm{~mm}$ mesh, were opened sequentially while the net was being hauled in, so that the water column was sampled in discrete depth intervals of $\leq 20 \mathrm{~m}$. The net was lowered at $0.5 \mathrm{~m} \mathrm{~s}^{-1}$ and raised at $0.2 \mathrm{~m} \mathrm{~s}^{-1}$; the towing speed was $2.5 \mathrm{knots}$. The deployments took an average of $40 \mathrm{~min}$ and were carried out every $3 \mathrm{~h}$ for $30 \mathrm{~h}$ between 4 and 5 July 1996, and 16 and 17 March 1997. Samples were immediately frozen at $-30^{\circ} \mathrm{C}$ for further analysis in the home laboratory. The same net-system was used on board the RV 'Calanus', although the total number of depth intervals was reduced to $6,(130$ to $100 \mathrm{~m}, 100$ to $75 \mathrm{~m}, 75$ to $50 \mathrm{~m}, 50$ to $30 \mathrm{~m}, 30$ to $15 \mathrm{~m}$, and 15 to $0 \mathrm{~m})$. The net was deployed successfully in visits made between June 28 and July 2, 1999, 4 and 8 October 1999, 6 and 8 March 2000, and 8 and 12 May 2000. A failure in the conducting cable in visits made between August 9 and 12, 1999 and November 29 and December 3, 1999 prevented communication with the MOCNESS and disabled any depthdiscrete sampling capability. In these instances, just 1 of the 9 nets was left open for the entire duration of the haul, and $150 \mathrm{~m}$ of cable was paid out at $0.5 \mathrm{~m} \mathrm{~s}^{-1}$ and hauled in at $0.2 \mathrm{~m} \mathrm{~s}^{-1}$. Subsequent calibration hauls with a VEMCO TDX attached to the MOCNESS frame estimated that the net reached a maximum depth of $60 \mathrm{~m}$. The towing speed was 2.5 knots. Temperature and salinity profiles were taken with a Neil Brown conductivity temperature depth (CTD) recorder in June and August 1999, and with a SeaBird CTD in all other visits. The attenuation coefficient was measured with a diffuselight transmissometer and a Secchi disk.

A $300 \mathrm{kHz}$ Workhorse ADCP was deployed from June 24, 1999 to July 4, 2000 in Inchmarnock Water (Fig. 1). The instrument was deployed on a U-shaped mooring and looked upwards from a depth of $110 \mathrm{~m}$. The instrument operated continuously over this period, with the exception of $5 \mathrm{~d}$ interludes for servicing every 2 mo. It was set to collect 15 depth 'bins' of $8 \mathrm{~m}$ depth, and to ping 12 times every $2 \mathrm{~min}$. The first $4 \mathrm{~m}$ above the ADCP were not resolved because of the ringing of the transducer after the transmit pulse, while the region close to the surface was excluded from the final data set because of surface reflection.

A LI-COR 200SA pyranometer was placed on an unobstructed rooftop in Tarbert, approximately $20 \mathrm{~km}$ away from the study site, to measure global solar radiation (sun plus sky; $\mathrm{W} \mathrm{m}^{-2}$ ).

Home laboratory analysis. During the 1996 and 1997 campaigns, all morphometric analyses were carried out on thawed specimens. The principal measurement was of the carapace (tip of the rostrum to the postero-lateral border; summer $n=3098$; winter $n=2464$ ), which was considered the most reliable estimate of body size given the damage that occurred to other body parts as a result of the freeze-thaw process. A calibration curve, used to derive 'total length' (front of the eye to tip of the telson), was obtained from undamaged specimens $\left(\mathrm{N}=664, \mathrm{r}^{2}=0.71\right)$. In the 1999 to 2000 campaigns, 'total length' was measured on fixed specimens $(\mathrm{N}=12056)$ approximately 6 mo after capture. The sexual development of all animals was staged according to Makarov \& Denys (1981). 
Length-frequency analysis. Overlapping modes were identified within length frequency distributions using component-fitting software (MIX 3.1; MacDonald \& Green 1988). The method finds the best fit to the length-frequency distribution through iterating between a series of component types (normal, lognormal, exponential and gamma). The user must identify the expected number of components within the distribution before initialising the fitting routines. A quasi Newton algorithm performed the fitting procedures without any constraints being placed on the proportions, the mean length or the variance expected within each component. I experimented with all types of curves and made the a priori assumption that there were either 2 or 3 modes in the population.

Acoustic analysis. Although designed principally to measure water velocity through the water column, the ADCP also collects information on the intensity of the returning echo from the ADCP's transmit pulse, which Flagg \& Smith (1989) showed to be correlated with zooplankton biomass in some instances. Tarling et al. (2002) analysed echo intensity (converted to absolute backscattering strength $\left[\mathrm{S}_{\mathrm{v}}\right]$ ) from the 1999-2000 Clyde Sea ADCP deployments and found that, at a threshold of $-70 \mathrm{~dB}$, there was a single sound scattering layer (SSL) in the water column, which was dominated by Meganyctiphanes norvegica. The modal length of krill was approximately $35 \mathrm{~mm}$, which gives a target strength (TS) of $-69 \mathrm{~dB}$ at $300 \mathrm{kHz}$, following Greene et al. (1991). Assuming the majority of backscatter in the SSL was caused by krill, the layer contains densities in excess of 1 ind. $\mathrm{m}^{-3}$. In the present study, it was assumed that the diurnal movements of an SSL over the course of the year represented the annual change in DVM pattern of the population of $M$. norvegica. Data were averaged over $6 \mathrm{~d}$ to minimise the effect of spatio/temporal patchiness on results. The respective arrival and departure of an SSL into and out of the surface layers was believed to indicate when vertical migration was occurring. Peaks in the relative change of echo intensity in the surface layers during dusk and dawn were good indicators of when migration occurred each day. The residence depths of krill outside of migration periods were determined through a combination of acoustic and net-catch information.

Model structure. Predation risk: Approach: Predation and starvation are the main causes of mortality in zooplankton such as krill. The risk of starvation was taken in to account through determining the expected energy intake (see 'Energy balance for a typical day in summer'). Visual fish predators were assumed to be the main cause of predation, but other visual predators, such as diving seabirds, may also have contributed, and are likely to present similar patterns of risk to vertically migrating krill (i.e. increasing closer to the surface). A generalised mortality risk function was applied (Giske et al. 1994) which took in to account irradiance, the light extinction coefficient and predator visual acuity. Direct estimation of the density of predators was not possible, so an iterative fitting-procedure was employed to derive the most likely value. This was believed not to have a major impact on model results, since only relative levels of mortality between sexes was being considered. Nevertheless, subsequent sensitivity analyses examined the importance of this step on model predictions.

Parameterisation: Irradiance was determined by the year-long record obtained at a nearby land-base, while the attenuation coefficients were estimated for every cruise carried out between 1999 and 2000 (see 'Overview'). Predator visual-acuity was estimated using a function for a general fish predator (Giske et al. 1994). The fitting procedure to derive predator density involved several steps. The first step was to determine the annual mortality rate for adult krill, which was carried out through comparing the relative abundance of the 1 and 2 yr old components in the adult population. Because of the potential confounding influence of $3 \mathrm{yr}$ olds on these components, this analysis was carried out on samples taken in June, when most of the $3 \mathrm{yr}$ olds had probably died out (Mauchline 1960). The second step was to find a predator density that resulted in a matching annual mortality rate. An arbitrary predator density was inserted into the predation risk algorithm, and a matrix of risk, as a function of time and depth, was constructed for a $1 \mathrm{yr}$ period. Model krill were then run through this matrix following an 'average' DVM profile (i.e. one that was representative of the entire population, based on net catch and acoustic information through the year). The process resulted in an estimate of the total risk of predation encountered by an 'average' krill over a year, which was assumed to be equivalent to the annual mortality rate. The predator density was increased or decreased by a small amount (increments of $5 \times 10^{-5} \mathrm{~m}^{-3}$ ), and the process repeated. The predator density that produced an annual mortality rate closer than any other to the estimate made by the component analysis in Step 1 was used in all further runs, with the exception of certain sensitivity analyses.

The 'average' DVM pattern was replaced by sexspecific DVM trajectories, derived from net catches (see 'Results'), to determine how mortality may differ between males and females as a result of their respective vertical migration behaviours. The model was run from 1 March, which was approximately the day of male and female maturation (Tarling \& Cuzin-Roudy 2003). Each run estimated the relative proportion of males and females remaining on each day of the year, 
which, in turn, gave the sex ratio. This approach made the following assumptions, that: (1) the male-to-female ratio was 1:1 at the start of the season, i.e. the point at which juvenile krill matured into adulthood; (2) the concentration of predators did not vary significantly over the course of the year; (3) the predators did not prefer one sex above the other, given that all other factors were equal; $(4)$ the predators followed their prey population perfectly, such that the predator density experienced by the prey was always equal over depth and time. This meant that the main factor altering risk was a change in the visual range of the predator as light varied with depth and time; and (5) that other sources of mortality (e.g. tactile predation) were not significant in terms of the decline of one sex relative to the other in the population;

Each of these assumptions was probably violated to a certain extent within the field situation. Therefore, parameters relating to the timing of DVM, predator density and distribution, sex ratio and seasonal variability were varied, within reasonable bounds, to investigate the effect of these assumptions on predictions. The fit of the original model, as well as the sensitivity runs, to observations of sex ratio over the course of a year was assessed by calculating the sum-ofsquares difference (SS):

$$
\mathrm{SS}=\sum_{i=1}^{n}\left(Y_{\mathrm{pre}, i}-Y_{\mathrm{obs}, i}\right)^{2}
$$

In total, there were 7 observations of sex-ratio $\left(Y_{\text {obs }}\right)$ over the course of $1 \mathrm{yr}$, which were compared with the predicted value $\left(Y_{\text {pre }}\right)$ for those dates. Observations in August and December were taken from net samples at a maximum depth of $60 \mathrm{~m}$. This did not violate the validity of samples taken in December, since the entire population was above this depth at night, when samples were taken. However, a small fraction of the population was below this depth at night in August, so this time point was excluded from the calculation of SS in both the original and the sensitivity runs, reducing $Y_{\text {obs }}$ to 6 . The effect of the sensitivity run on goodness-of-fit was calculated as a \% improvement (plus) or worsening (minus) relative to the SS of the original run.

Energy balance for a typical day in summer: Approach: Energy balance is a product of food intake and assimilation efficiency, minus the cost of metabolism. The balance gives an indication of whether the krill are creating an energetic surplus, which can be invested in growth and reproduction, or running up a deficit, which will result in weight loss and ultimate starvation. Parameters for food availability, as a function of depth and time of day, and respiration rate, as a function of size and temperature, were only available for a typical summer situation. This is a particularly interesting time, given that it is the middle of the reproductive season (Tarling \& Cuzin-Roudy 2003), when differences between females and males should be particularly extreme.

Parameterisation: Tarling et al. (2000) determined a depth/time matrix for energy balance in the Clyde Sea during a typical summer situation. Food intake was derived from functional responses to copepod and phytoplankton prey items, whose concentrations were determined empirically from net samples taken during the 1996 campaign (values already published in Lass et al. 2001). Metabolism was derived from in situ measurements of respiration rate (values in Saborowski et al. 2002). The empirically derived DVM of males and females during that period (see 'Results') was run through this matrix to predict the net energy balance that would have resulted. The range of temperatures experienced by krill over the course of DVM was assumed not to affect feeding. The net energy gain of males and females was compared to determine the relative pay-off of adopting their respective DVM trajectories.

\section{RESULTS}

\section{Abiotic environment}

The deep trench region of the Clyde Sea Area underwent thermal stratification during the annual cycle (Fig. 2a). The stratification started during midApril, when the surface waters warmed to ca. $1^{\circ} \mathrm{C}$ higher than the rest of the water column. A thermocline with a gradient of up to $4^{\circ} \mathrm{C}$ became apparent at $20 \mathrm{~m}$ between mid-June and mid-September. Surface temperatures peaked at $15^{\circ} \mathrm{C}$ during midAugust, from which point onwards temperatures declined as a result of the breakdown of the thermocline and the mixing of surface waters with the cooler, deeper layers. The entire water column became thermally mixed by November, eventually reaching a minimum temperature of $8^{\circ} \mathrm{C}$ by the start of March. The Clyde Sea receives freshwater from a large catchment area, which acts to decrease the salinity of the surface layers (Fig. 2b). This effect becomes most pronounced when mixing is restricted during the presence of the thermocline. The salinity of the surface waters reached a minimum of 32 PSU during mid-August, which was 1.5 PSU below levels in the lower depth strata. This gradient reduced to 1 PSU once the thermocline had broken down. Overall, neither temperature nor salinity depth-gradients were particularly strong, so their influence on behaviour, metabolism and growth as a result of variations in DVM trajectories was believed not to play a major role. 

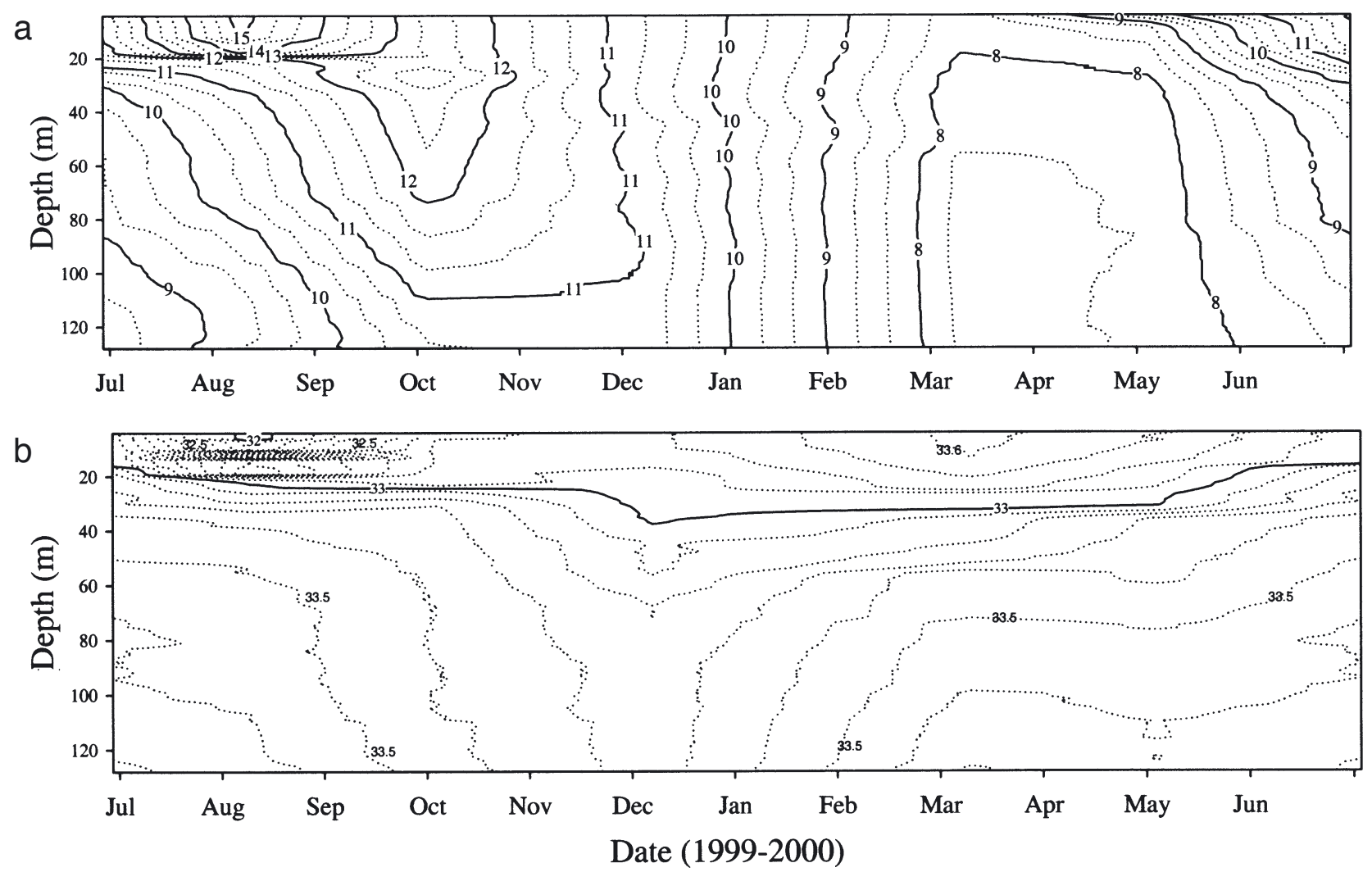

Fig. 2. (a) Temperature and (b) salinity in the Clyde Sea deep trench between the summers of 1999 and 2000

\section{Acoustic analysis}

Echo intensity was significantly higher within the SSL (Mann-Whitney, p < 0.001), equating to krill densities of between 1 and 8 ind. $\mathrm{m}^{-3}$ (using a TS of $-69 \mathrm{~dB})$. Outside of the SSL, krill densities were less than 1 ind. $\mathrm{m}^{-3}$. In Fig. 3a, the vertical location of maximum echo intensity was plotted for every 2 min interval over $24 \mathrm{~h}$, as a simplified illustration of how the SSL migrated vertically over the diel cycle. Maximum echo intensity resided between 60 and $90 \mathrm{~m}$ during the daytime, and between the surface and $30 \mathrm{~m}$ during the night, with migration between these 2 depth-zones lasting ca. 30 min during both the upward and downward phases. The movement of the SSL into and out of the surface layers resulted in peaks in the rate of change of echo intensity, a positive peak marking its arrival and a negative peak, its departure (Fig. 3b). These points were extracted for each day of the year and plotted against the nautical times of sunrise and sunset for the Clyde Sea (Fig. 4). It can be seen that the times of arrival and departure were generally after sunset and before sunrise, the intervening interval being ca. 30 min in both instances. Fig. 4 also shows that there were some seasonal variations in the extent of these intervals. Most notable was between the start of April and the end of June, where descent was up to 90 min before sunrise (Fig. 4b), a change in behaviour that may reflect the onset of adult reproductive activity. These empirical observations were combined to represent the DVM behaviour of Meganyctiphanes norvegica throughout the year.

\section{Net catch: DVM analysis}

Information from net-catches shows that both the female and male northern krill performed DVM in winter as well as in summer (Fig. 5). In the summers of both 1996 and 1999, over $90 \%$ of the individuals of both sexes rested between 60 and $100 \mathrm{~m}$ during the day. During summer, females were less likely to stay deeper than males (10 vs $33 \%$, respectively), and more likely to be found in the uppermost depth intervals (20 to $40 \%$ vs 4 to $15 \%$, respectively). In winter, males and females showed comparatively less spread in their choice of depth, with fewer males showing a tendency to remain in the deep layers during the night. Nevertheless, the percentage of females reaching the uppermost depth interval at night was still double $(8 \%)$ that of males $(4 \%)$. 

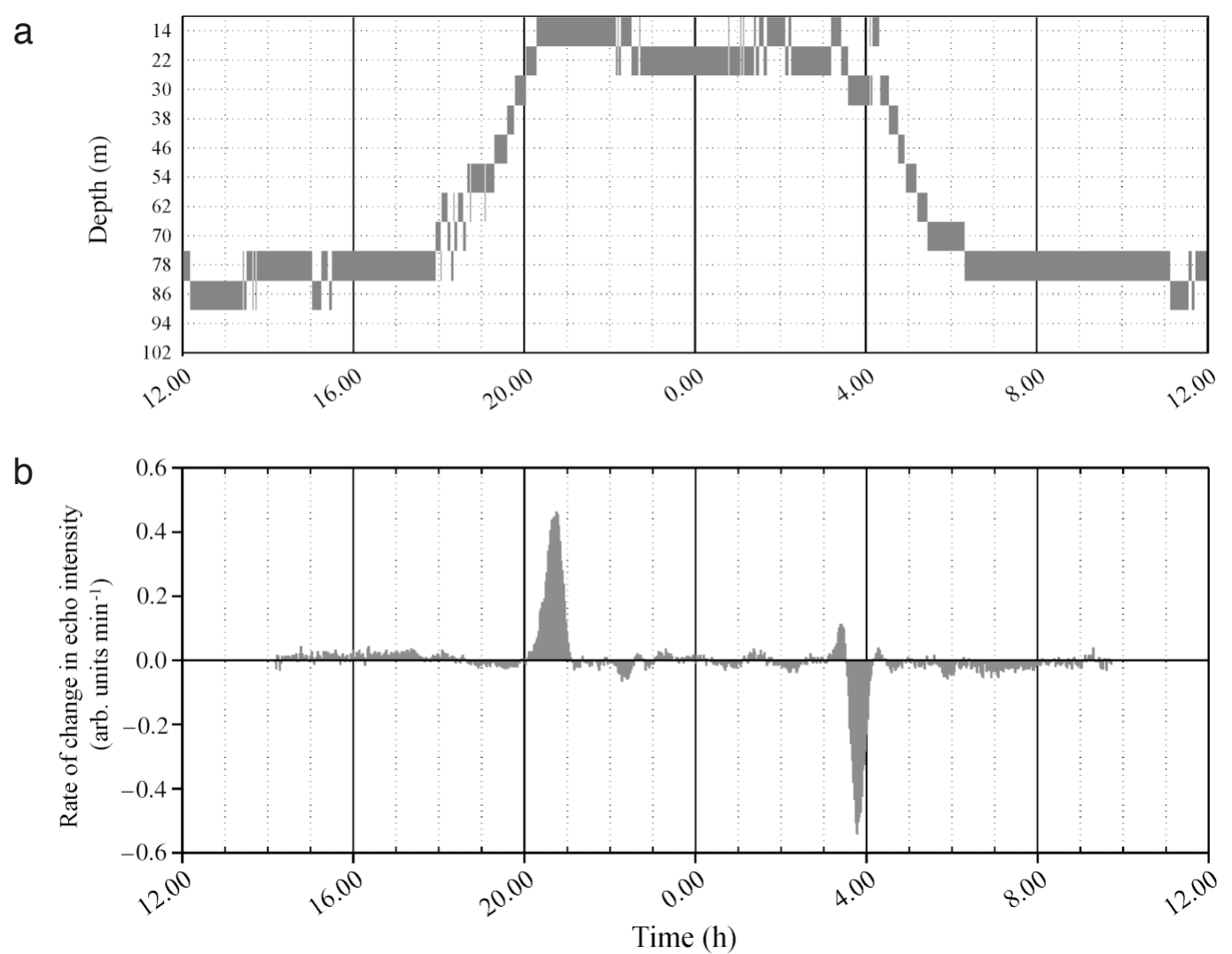

Fig. 3. (a) Vertical distribution of peak echo-intensity over a diel cycle; (b) rate of change in echo intensity between 10 and $18 \mathrm{~m}$ for a typical day in summer. Data for both graphs were taken between 23 and 29 August 1999, and averaged to give a single representative day

Females migrated closer to the surface at night than males of equivalent size (Fig. 6). In the smaller size categories $(<33$ to $35 \mathrm{~mm})$, the females reached a minimum nighttime depth that was ca. $20 \mathrm{~m}$ higher than that of males. For individuals between 35 and $37 \mathrm{~mm}$, this difference increased to $30 \mathrm{~m}$, while the minimum depth achieved by individuals between 37 and $39 \mathrm{~mm}$ differed by over $40 \mathrm{~m}$, depending on their sex. The difference was not so great for the largest size category $(>39 \mathrm{~mm})$. During the daytime, average depth of males and females overlapped to the extent that no differences could be discerned in any size class.

Size played less of a role in determining nighttime depth in females than in males (Fig. 7). The difference between minimum and maximum depth during nighttime was ca. $20 \mathrm{~m}$ in females, but ca. $50 \mathrm{~m}$ in males. This was mainly because the 37 to $39 \mathrm{~mm}$ size class in males showed an average depth that was consistently deep, both night and day. In both sexes, smaller individuals were found closer to the surface at night, but less so during the day when the depth distribution of the population was more compact.

\section{Net catch: population analysis}

Through a large part of the year, the adult population was comprised of 2 age classes, 1 yr olds (Group I) and 2 yr olds (Group II; Fig. 8). If 3 yr olds were present in the population, they were not distinguishable in terms of length from 2 yr olds. Most newly spawned individuals spent their first winter as juveniles but, by March (Fig. 8e), the majority of these had matured into adults (Group I). As the productive season progressed, Group I grew and constituted an increasing proportion of the adult population as the numbers of Group II declined. In June, for instance (Fig. 8a), Group II made up less than 1/4 of the numbers of Group I, while in August (Fig. 8b), Group II was not present at all. Between August and December, Group I was the principal adult age class, although some young adults (Group 0) had started to emerge from the earliest spawning episodes of that year. The Group II identified in the March 2000 samples (Fig. 8e) was the remnant of Group I identified the previous December (Fig. 8d).

Annual mortality rate was estimated through determining the relative abundance of the components of 

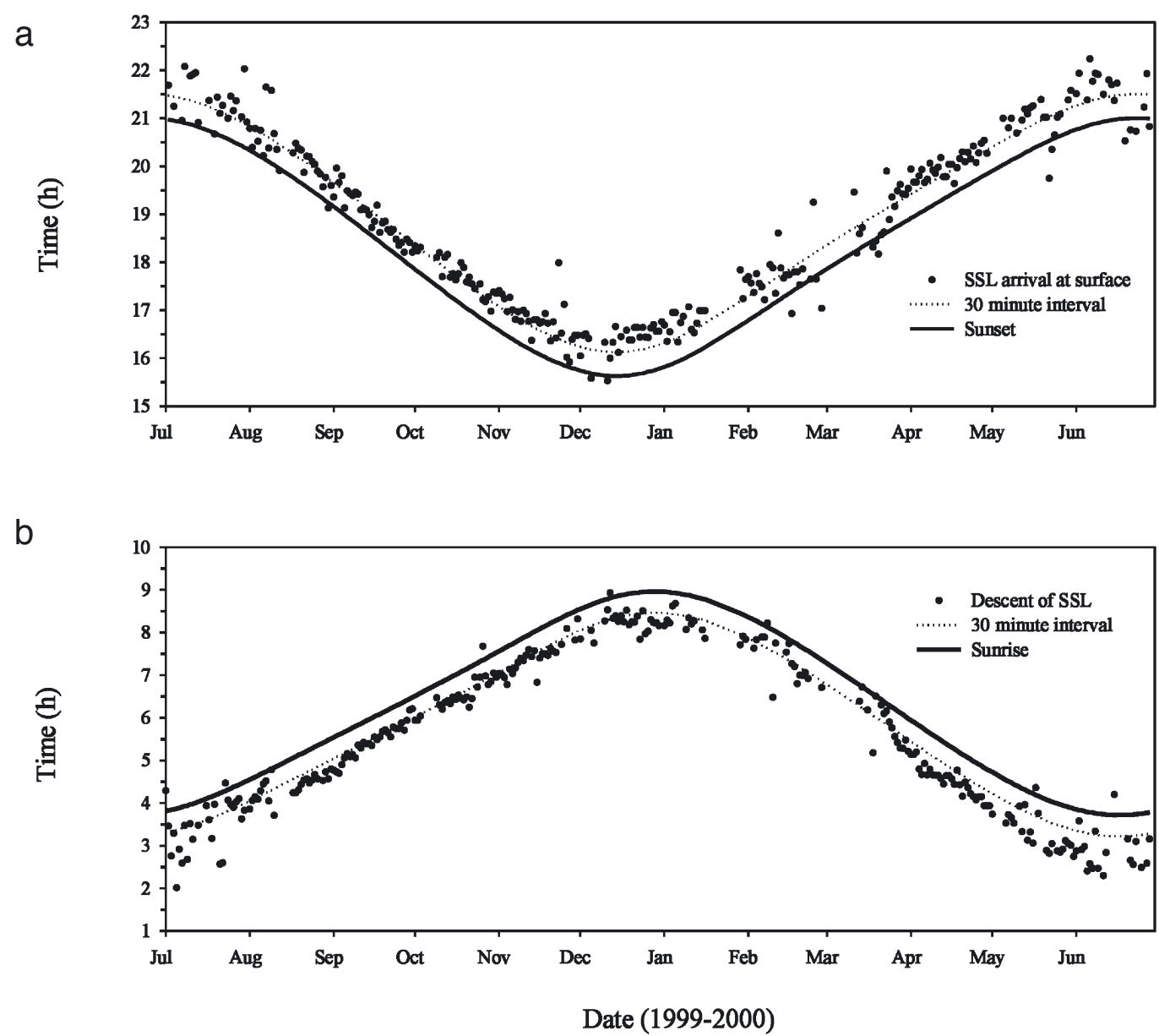

Fig. 4. (a) Correspondence between time of sunset and time of arrival of the Meganyctiphanes norvegica-dominated sound scattering layer (SSL) in upper layers; (b) correspondence between time of sunrise and time of departure of SSL from upper layers

Groups I and II in June 1999. This month was chosen to minimise the confounding influence of 3 yr olds on the calculation. The abundance of Group II was $36 \%$ the abundance of Group I during this period, with the decrease being more apparent in females (Group II = $23 \%$ of Group I's abundance) than in males (Group II = $46 \%$ of Group I's abundance). I assumed that the population decreased as a negative exponential over the course of the year:

$$
N_{t+365}=N_{t}^{-365 \beta}
$$

where $N$ is the number of individuals, $t$ is time in days and $\beta$ is the mortality coefficient per day. Accordingly, the daily mortality rate $(\beta)$ of the entire adult population would have been $0.003 \mathrm{~d}^{-1}$, of which the rate for females would have been $0.004 \mathrm{~d}^{-1}$ and that for males $0.002 \mathrm{~d}^{-1}$

Very little somatic growth, in terms of total length, was apparent in either males or females in the summer and autumn (Table 1). The modal size class of Group I, the principal adult component during this time, remained at ca. 34 to $35 \mathrm{~mm}$ in both sexes over this entire period. By the end of the winter period, the principal modal class of this cohort was $2 \mathrm{~mm}$ smaller in both males and females, suggesting that either sizedependent mortality or shrinkage had taken place during the winter. Rapid growth ensued in the spring, with the modal size class of newly matured adults (Group I) increasing from $22 \mathrm{~mm}$ to $31 \mathrm{~mm}$ between early March and early May. Group II grew at a similar rate over this same period, with males increasing by $4 \mathrm{~mm}$ and females by $5 \mathrm{~mm}$. The males still remaining in Group II by June had a slightly greater mass, but were the same length, as the remaining females. Generally, both sexes grew at similar rates over the life cycle.

The lower mortality rate of males resulted in them becoming increasingly dominant, in terms of relative abundance, through time (Table 2). At the point of maturity from juvenile to adulthood, the sex ratio of the cohort was slightly in favour of females (0.8:1), although it is to be noted that a small fraction of the cohort had yet to mature. Within $2 \mathrm{mo}$, the sex ratio 

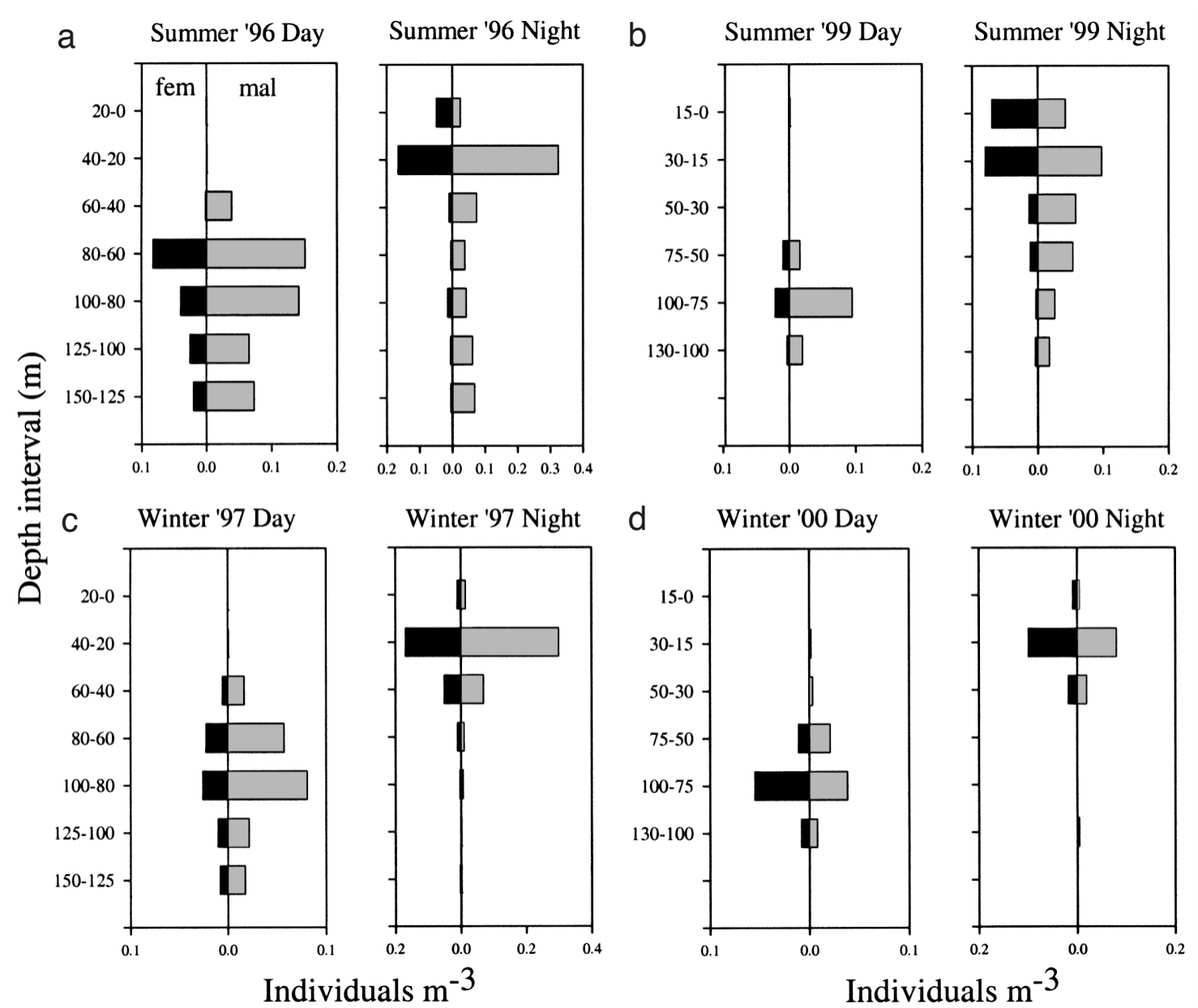

Fig. 5. Meganyctiphanes norvegica. Vertical distribution of females (black) and males (grey) during the day and night in the summers of (a) 1996 and (b) 1999 and subsequent winters (c) 1997 and (d) 2000

had swung in favour of males, and by August, males made up $55 \%$ of the cohort. By December, there were 2.6 males for every female, but after winter the male fraction of this same cohort had decreased by $11 \%$ relative to the number of females, suggesting that females were more successful at over-wintering. Nevertheless, males were more able than females to survive the following spring and summer, since, close to the end of their lifecycle, they outnumbered females by around 3 to 1 .

\section{Sex-dependent DVM model}

Empirical results showed that: (1) DVM was performed through the
Table 1. Meganyctiphanes norvegica. Total length ( $\mathrm{mm})$ and dry weight (mg, in parentheses) of the modal size class of cohorts present during each campaign from 1999 to 2000. Total length (TL) was converted to dry weight (DW) using empirically derived relationships (female: $\mathrm{DW}=0.0013 \times \mathrm{TL}^{3.01}, \mathrm{R}^{2}=0.84$; male: $\mathrm{DW}=0.0023 \times \mathrm{TL}^{2.90}, \mathrm{r}^{2}=0.71$ ) na: not applicable because the age group was not present at that time

\begin{tabular}{|llccc|}
\hline Date & Sex & Group 0 & Group I & Group II \\
\hline 28 Jun to 2 Jul 1999 & Female & na & $34(52.7)$ & $38(73.8)$ \\
& Male & na & $34(63.5)$ & $38(87.7)$ \\
9-16 Aug 1999 & Female & na & $34(52.7)$ & na \\
& Male & na & $35(69.1)$ & na \\
4-8 Oct 1999 & Female & $28(29.3)$ & $34(52.7)$ & na \\
& Male & $28(36.2)$ & $35(69.1)$ & na \\
29 Nov to 3 Dec 1999 & Female & No modal peak & $34(52.7)$ & na \\
& Male & No modal peak & $35(69.1)$ & na \\
6-8 Mar 2000 & Female & na & $22(14.2)$ & $32(43.9)$ \\
& Male & na & $22(18.0)$ & $33(58.3)$ \\
8-12 May 2000 & Female & na & $31(39.9)$ & $36(62.7)$ \\
& Male & na & $31(48.6)$ & $38(87.7)$ \\
\hline
\end{tabular}



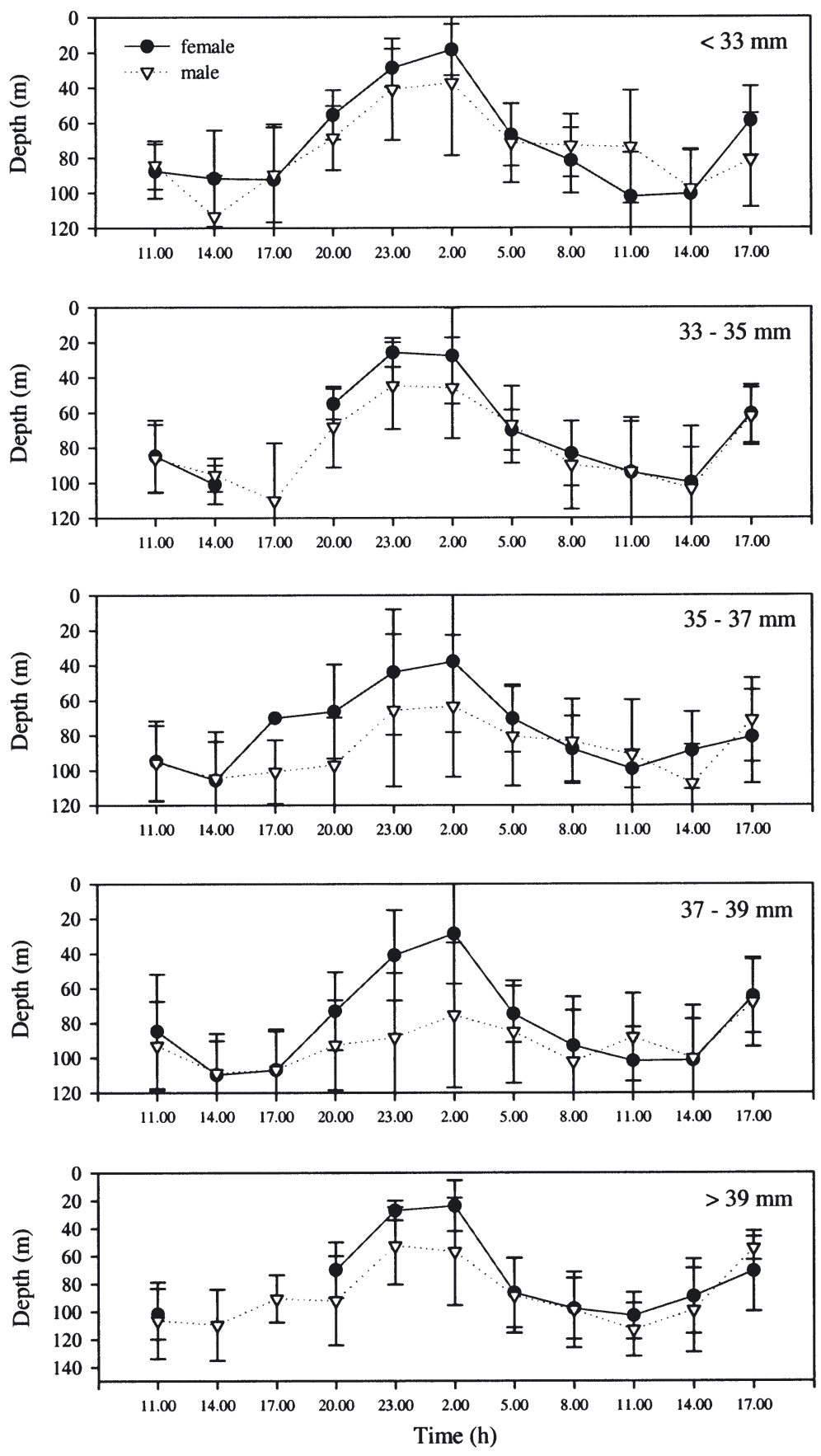

Fig. 6. Meganyctiphanes norvegica. Comparison of the average depth of males and females of the same size class over a diel cycle during summer 1996. Error bars denote $\pm 1 \mathrm{SD}$

entire year; (2) the main part of the population arrived at the surface ca. 30 min after sunset and departed 30 min before sunrise; (3) females and males remained at approximately the same depth during the day; and (4) females were more likely to go above $15 \mathrm{~m}$ depth during the night, while males mostly remained below this depth.
Model DVM trajectories were designed so that these 4 main features were incorporated. The water column was divided into the same 6 depth intervals sampled by net deployments in the 1999-2000 campaign series, to allow direct correspondence between predictions and observations (see 'Materials and methods'). Both males and females remained in the 75 to $100 \mathrm{~m}$ depth interval during the daytime. The model krill moved to the 50 to $75 \mathrm{~m}$ interval 90 min before sunset, arriving at the 30 to $50 \mathrm{~m}$ interval $1 \mathrm{~h}$ later. Both males and females arrived in the 30 to $15 \mathrm{~m}$ interval 30 min after sunset, where the males remained for the rest of the night. Females continued to ascend until reaching the 0 to $15 \mathrm{~m}$ interval, $90 \mathrm{~min}$ after sunset. The females remained there for the rest of the night and rejoined the male population in the 30 to $15 \mathrm{~m}$ interval $90 \mathrm{~min}$ before sunrise. Both males and females descended from this interval $30 \mathrm{~min}$ before sunrise, moving through the depth intervals at the same rate as they ascended. They reached the 75 to $100 \mathrm{~m}$ depth interval $90 \mathrm{~min}$ after sunrise. The exact timings of these migrations altered through the year as a result of the seasonal shift in the solar cycle, such that, in midsummer, females spent just $4 \mathrm{~h}$ in the 0 to $15 \mathrm{~m}$ depth interval, while in mid-winter, they spent $13 \mathrm{~h}$ there.

The predicted sex ratio increased in favour of males over the course of the year (Fig. 9). From a 1:1 ratio at the start of March, the model predicted that there would be 1.6 males for every female after $4 \mathrm{mo}$, and twice as many males as females after 6 mo. By the end of the year, the predicted sex ratio was above 4:1 (male:female). The predictions fitted observations particularly well during the first $6 \mathrm{mo}$, with almost all the observed sex ratios being placed close to the predicted trajectory. However, predicted male-to-female ratios were higher than observed during winter (Day 240 onwards), indicating that either male mortality had been underestimated or female mortality overestimated during that period. Overall, the model predicted that $17 \%$ of females and $70 \%$ of males would remain after $1 \mathrm{yr}$ (Table 3), making the mortality coefficients $(\beta) 0.005$ and $0.001 \mathrm{~d}^{-1}$ respectively, when averaged over the whole year. With respect to component-analysis estimates, made on empirical data (see above), predicted female mortality rate was overestimated by $0.001 \mathrm{~d}^{-1}$, while predicted male mortality was underestimated by the same amount. 

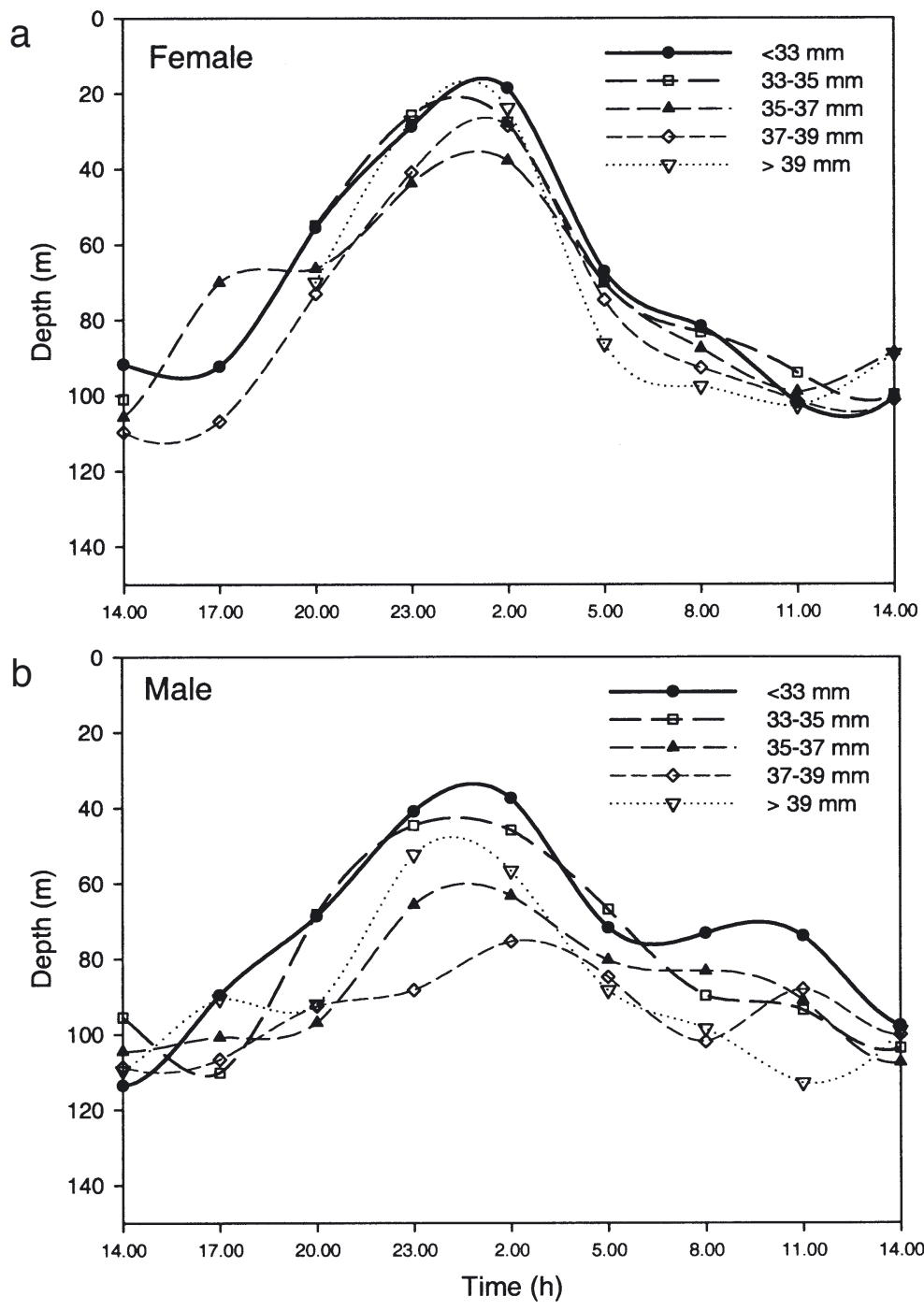

Fig. 7. Meganyctiphanes norvegica. Average depths of different size classes of (a) females and (b) males over a diel cycle during summer 1996. Standard deviation (SD) is not displayed, to aid clarity, but can be gauged through reference to Fig. 6, which is a rearrangement of the same data
Run A for females and Run B for males) had a devastating effect on the mortality of both females and males, making them extinct within the course of a year. By comparison, reducing the time in the upper layers by ascending an hour later and descending an hour earlier (Run C for females and Run D for males) made less of a difference, especially with respect to females, in which the goodness-of-fit altered by less than $5 \%$ compared with the original model run. Altering just the ascent or descent time (Run E and $F$, respectively, for females; Run $G$ and $H$, respectively, for males) showed that it was the time of ascent that made the greatest difference to mortality levels. Empirical observations of descent times showed that there was an increasing lead between time of descent and sunrise between the start of April and end of June (Fig. 4). Applying this variability to the model made very little difference to predicted mortality (Run I).

The model assumed that northern krill spawn eggs with a genotypic sex ratio of $1: 1$. There is no evidence yet available to contradict this assumption, but in March, when most (but not all) of the juvenile population had matured into adulthood, the female:male sex ratio was 0.8:1. The most likely explanation is that females mature later than males, and the sex-ratio would be restored to 1:1 once all the juveniles had matured. However, the effect of a genotypic bias in the population was tested by initialising the model with a sex ratio of $0.8: 1$ (Run J). The females remaining after 1 yr was $12 \%$ (relative to the initial size of the male population), $5 \%$ below the original model prediction and $11 \%$ below the component-analysis estimate. Therefore, the assumption of a biased genotypic sexratio did not improve goodness-of-fit to observations.

\section{Influence of model parameterisation on predicted sex-ratios}

Table 3 illustrates some of the major sensitivities of model predictions to parameterisation. Goodnessof-fit was particularly sensitive to the time of arrival and departure from the surface layers. Increasing the amount of time spent in the upper layers by ascending an hour earlier and descending an hour later (Sensitivity
Table 2. Meganyctiphanes norvegica. Male-to-female sex ratio of different age classes (Groups I and II), and the fraction of the population entering the upper water column; na: not applicable because the age group was not present at that time

\begin{tabular}{|lccc|}
\hline Date & Group I & Group II & $\begin{array}{c}\text { Upper water column } \\
\text { (Groups I and II) }\end{array}$ \\
\hline 28 Jun to 2 Jul 1999 & 1.6 & 2.8 & 0.6 \\
9-16 Aug 1999 & 2.1 & na & na \\
4-8 Oct 1999 & 2.3 & na & 0.9 \\
29 Nov to 3 Dec 1999 & 2.6 & na & 0.8 \\
6-8 Mar 2000 & 0.8 & 1.6 & 0.8 \\
8-12 May 2000 & 1.3 & 3.6 & 0.9 \\
\hline
\end{tabular}



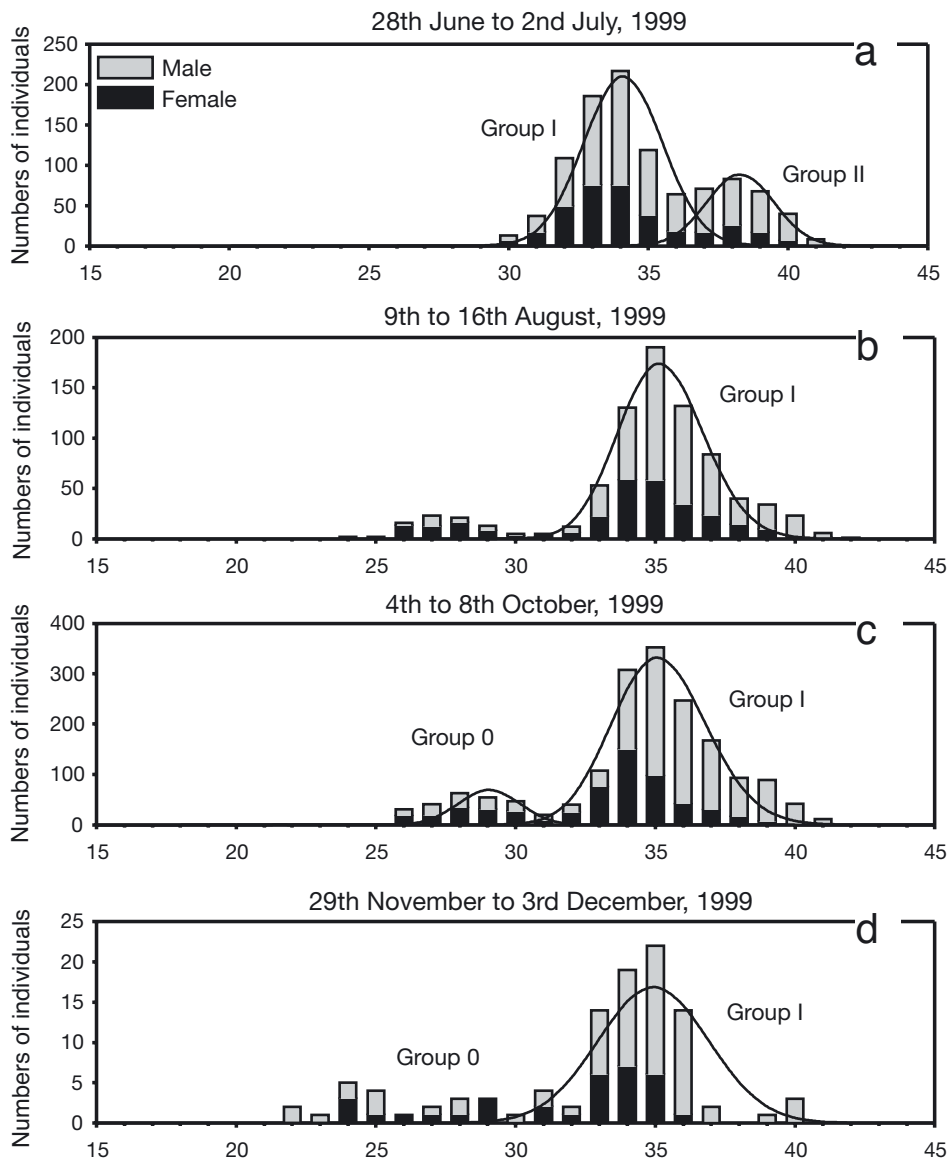

\section{Overwinter}
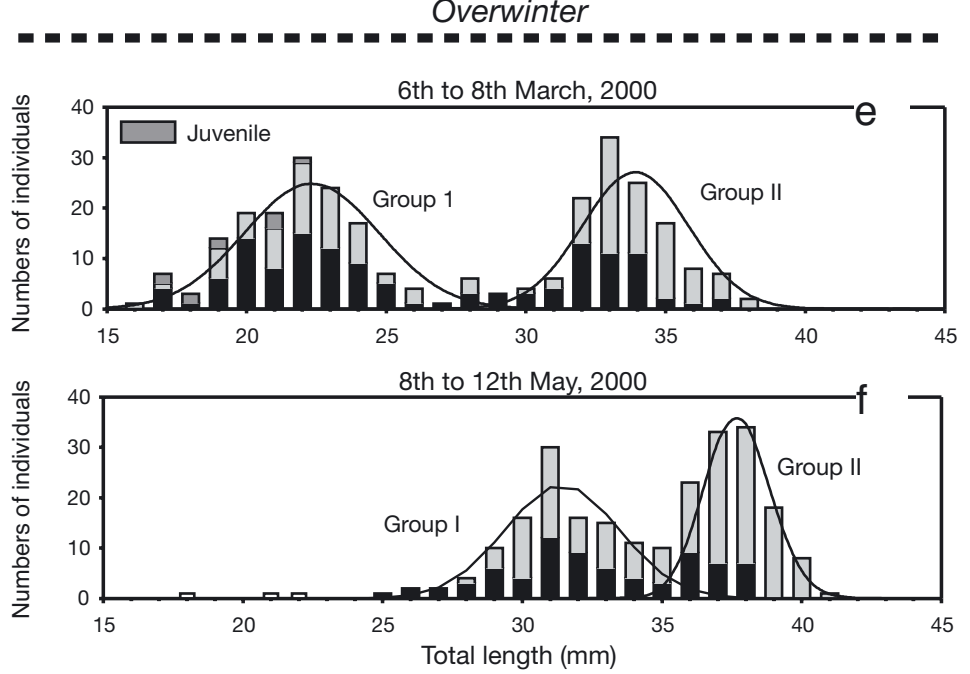

Fig. 8. Meganyctiphanes norvegica. Size frequency of adults through 1999 to 2000 campaigns. August and December samples contain exclusively those samples taken at night, to minimise any bias caused by maximum net depth being only $60 \mathrm{~m}$

Predator density was fitted in the original parameterisation because there were no appropriate empirical estimates available. Increasing predator density by an order of magnitude (Run K) made both the male and female populations extinct within a year. Decreasing the density by the same order (Run L) made the percentage of animals remaining after $1 \mathrm{yr}$ unfeasibly large. Altering the distribution of predators, so that they were twice as abundant in the upper layers and only half as abundant at depth (Run M), had almost no effect on goodness-of-fit.

Overall, model predictions were robust, so long as both males and females did not migrate up much earlier and migrate down much later than parameterised, and predator density did not differ persistently by an order of magnitude.

\section{Consequences of sex-dependent DVM}

The DVM trajectory of females achieved a greater net-energy gain than males (Table 3, last column). Respiration rate, which altered with temperature, differed very little between sexes, given the limited gradient within the thermocline. By contrast, daily energy intake differed greatly, with males assimilating $25 \mathrm{~J} \mathrm{~d}^{-1}$, while females assimilated $35 \mathrm{~J} \mathrm{~d}^{-1}$. Sensitivity analyses showed that females always gained more energy than males, even when the length of the night was shortened, so reducing the time available to feed at a high rate. The potential rewards for ascending closer to the surface therefore appeared to be relatively high.

\section{DISCUSSION}

Empirical observations showed that females typically ascended closer to the surface than males, and that over the course of the year, their numbers declined with respect to the male population. A model estimating the relative risk to visual predation, as a result of performing DVM, predicted a relative rate of decline of the male and female populations that matched well with observations during the spring, summer and autumn. The riskier DVM of females had a significant potential reward in terms of energy intake, supplementing that achieved by males by an extra $40 \%$, or $10 \mathrm{~J} \mathrm{~d}^{-1}$. Overall, this appears to be a good example of where an implied difference in the trade-off between reward and risk is observable in a field population.

The increasing dominance of males in the Clyde Sea population is not a universally observed phenomenon in Meganyctiphanes norvegica populations. In the Ligurian Sea, for instance, males and 


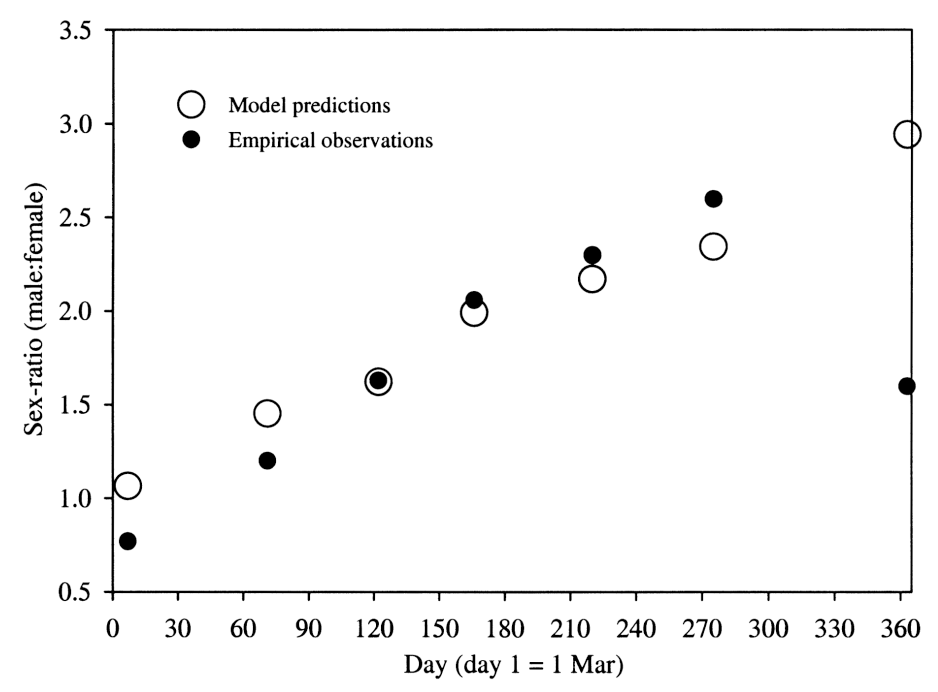

Fig. 9. Meganyctiphanes norvegica. Predicted (O) versus observed $(\bullet)$ sex ratios over an annual cycle. Model assumes that both sexes mature on 1 March and the genotypic sex ratio was $1: 1$

females were present in equal proportion throughout their year-long life-cycle (Labat \& Cuzin-Roudy 1999), whereas in the Kattegat, sex ratios reached up to 4:1 in favour of males (Boysen \& Buchholz 1984). Such variations highlight the importance of environmental conditions and predation to population dynamics. In the Ligurian Sea, krill migrate up from daytime depths, in excess of $500 \mathrm{~m}$, to settle eventually within the chl $a$ maximum layer, around $30 \mathrm{~m}$, at night (Anderson \& Nival 1991). The oligotrophic conditions in this environment (Boucher et al. 1987) allow light to penetrate relatively deep (Riley 1956), making the relative risk to

Table 3. Meganyctiphanes norvegica. Results of sensitivity analyses showing the goodness-of-fit, in terms of sums of square difference (SS) as a percentage relative to the SS of the original model (+ denoting an improved fit, - a worsened fit); $\%$ of females and males remaining after $1 \mathrm{yr}$; daily mortality coefficient $\left(\beta \mathrm{d}^{-1}\right)$, assuming that, on average, population decay over the course of the year followed a negative exponential function; and the difference between net energy gain of females and males in a typical summer situation (+ denoting female gain is greater than male); na - not applicable; DVM: diel vertical migration

\begin{tabular}{|c|c|c|c|c|c|c|c|}
\hline $\begin{array}{l}\text { Sensi- } \\
\text { tivity } \\
\text { run }\end{array}$ & $\begin{array}{c}\text { Alteration to } \\
\text { parameterisation }\end{array}$ & $\begin{array}{l}\text { SS relative to } \\
\text { original model } \\
\text { run }(\%)\end{array}$ & $\begin{array}{l}\text { Females } \\
\text { remaining } \\
\text { after } 1 \text { yr }(\%)\end{array}$ & $\begin{array}{c}\text { Males } \\
\text { remaining } \\
\text { after } 1 \text { yr }(\%)\end{array}$ & $\begin{array}{c}\beta \mathrm{d}^{-1} \\
\text { female }\end{array}$ & $\begin{array}{l}\beta d^{-1} \\
\text { male }\end{array}$ & $\begin{array}{c}\Delta \text { female and } \\
\text { male net energy } \\
\text { gain }\left(\mathrm{J} \mathrm{d}^{-1}\right)\end{array}$ \\
\hline & Observations, June 1999 & - & 23 & 46 & 0.004 & 0.002 & na \\
\hline & Original model run & - & 17 & 70 & 0.005 & 0.001 & +9.9 \\
\hline A & $\begin{array}{l}\text { Females stay in upper } \\
\text { layers } 2 \mathrm{~h} \text { longer }\end{array}$ & & \multicolumn{4}{|c|}{ Female population became extinct } & +17.2 \\
\hline B & $\begin{array}{l}\text { Males stay in upper } \\
\text { layers } 2 \mathrm{~h} \text { longer }\end{array}$ & & \multicolumn{4}{|c|}{ Male population became extinct } & +5.0 \\
\hline $\mathrm{C}$ & $\begin{array}{c}\text { Females stay in upper } \\
\text { layers } 2 \mathrm{~h} \text { less }\end{array}$ & -4.3 & 49 & 70 & 0.002 & 0.001 & +0.9 \\
\hline $\mathrm{D}$ & $\begin{array}{l}\text { Males stay in upper } \\
\text { layers } 2 \mathrm{~h} \text { less }\end{array}$ & -169.8 & 17 & 99 & 0.005 & 0.0001 & +15.2 \\
\hline E & $\begin{array}{l}\text { Females leave upper } \\
\text { layers } 1 \mathrm{~h} \text { earlier }\end{array}$ & +35.6 & 20 & 70 & 0.004 & 0.001 & +4.6 \\
\hline $\mathrm{F}$ & $\begin{array}{c}\text { Females arrive in upper } \\
\text { layers } 1 \mathrm{~h} \text { later }\end{array}$ & +16.8 & 42 & 70 & 0.002 & 0.001 & +6.1 \\
\hline G & $\begin{array}{l}\text { Males leave upper } \\
\text { layers } 1 \mathrm{~h} \text { earlier }\end{array}$ & -2.8 & 17 & 71 & 0.005 & 0.001 & +13.0 \\
\hline $\mathrm{H}$ & $\begin{array}{l}\text { Males arrive in upper } \\
\text { layers } 1 \mathrm{~h} \text { later }\end{array}$ & -163.0 & 17 & 99 & 0.005 & 0.0003 & +12.1 \\
\hline I & $\begin{array}{l}\text { Increased variability in } \\
\text { DVM in spring }\end{array}$ & +22.5 & 19 & 70 & 0.005 & 0.001 & na \\
\hline $\mathrm{J}$ & $\begin{array}{l}\text { Initial female:male } \\
\text { sex ratio } 0.8: 1\end{array}$ & -228.6 & 12 & 70 & 0.006 & 0.001 & na \\
\hline K & $\begin{array}{l}\text { Predator density } \\
\text { 10-times higher }\end{array}$ & & \multicolumn{4}{|c|}{ Male and female population became extinct } & na \\
\hline $\mathrm{L}$ & $\begin{array}{c}\text { Predator density } \\
\text { 10-times lower }\end{array}$ & -40.3 & 84 & 97 & 0.0005 & 0.0001 & na \\
\hline M & $\begin{array}{l}\text { Predator density } \\
\text { doubled above } 30 \mathrm{~m} \text {, } \\
\text { halved below } 30 \mathrm{~m}\end{array}$ & 0 & 12 & 62 & 0.006 & 0.001 & na \\
\hline
\end{tabular}


visual predation similar throughout the depths occupied whilst feeding. As a consequence, even if males and females chose slightly different feeding depths, the relative difference in risk would be negligible, so a sex-ratio bias would not be expected. In the Kattegat, environmental conditions are very similar to the Clyde Sea (Matthews et al. 1999), with food concentrated at the surface and light attenuated quickly with depth. A migration regime with greater energetic return will probably result in a greater risk of predation, assuming that there are sufficient visual predators present. If females must achieve a greater energetic profit than males, the observed dominance of males with age in this population is to be expected.

\section{Net-catch observations}

Sex was as important as size in determining the nighttime depth of an individual. The average depth of males and females between 37 and $39 \mathrm{~mm}$ differed by more than $40 \mathrm{~m}$ while, in other size categories, the average depth difference was between 20 and $35 \mathrm{~m}$. These differences were equivalent to size-related depth differences within each sex.

Mauchline (1960) observed that Meganyctiphanes norvegica shows size-dependence in the timing of its migration and its ultimate resident depth in the upper layers. De Robertis (2002) showed that the same pattern in Euphausia pacifica can be explained through assuming that larger individuals are more easily detected by visual predators. The influence of sex on the vertical distribution and DVM of euphausiids is not commonly reported, possibly because most studies deal with vertical migration of the whole population. Watkins \& Murray (1998) provide one of the only examples of depth-related sorting according to sex, in that they observed a 2-layered superswarm in which females dominated the upper layer. They did not investigate the significance of this pattern in relation to energy intake or predation risk.

\section{Predicted consequences of DVM}

The potential energetic profit resulting from the DVM of females during a summer situation was around $10 \mathrm{~J} \mathrm{~d}^{-1}$ more than that resulting from the DVM of males. Given that females and males are similar in size and have similar rates of somatic growth, such an energy supplement for females is presumably channelled in to reproduction. Maximising reproductive output is a sufficient reason to increase acceptable levels of risk, according to evolutionary theory (Mangel \& Clark 1988). However, the degree to which this energetic supplement can meet reproductive output needs to be established. Euphausiid eggs are lipid rich (Cuzin-Roudy et al. 1999). Pure lipid has an energetic content of $40 \mathrm{~J} \mathrm{mg}^{-1}$ ash-free dry weight (Cummins \& Wuycheck 1971) while lipid-rich zooplankton contain around $30 \mathrm{~J} \mathrm{mg}^{-1}$ ash-free dry weight (Prus 1975). The energetic content of euphausiid eggs lies somewhere between these values and can be assumed to be around $35 \mathrm{~J} \mathrm{mg}^{-1}$ ash-free dry weight. Cuzin-Roudy (2000) estimated that, on average, the ovary of Meganyctiphanes norvegica contains 1147 eggs with a combined wet weight of $18 \mathrm{mg}$, or $0.016 \mathrm{mg}$ wet weight per egg. Assuming that $10 \%$ of the egg is made up of ash and that the dry weight of the egg is $20 \%$ of the wet weight (Postel et al. 2000), the total energetic content of one egg is $0.1 \mathrm{~J}$, and that of the ovary is $115 \mathrm{~J}$. Mature oocytes are spawned in discrete events every other moult cycle (Cuzin-Roudy \& Buchholz 1999). The moult cycle was estimated to last $11 \mathrm{~d}$ at this time of year in the Clyde Sea (Tarling \& Cuzin-Roudy 2003), which means that an individual spawns after every $22 \mathrm{~d}$. Assuming that all the mature oocytes were spawned during this event, the daily energetic requirement to build up this amount of eggs would be $115 \mathrm{~J}$ divided by $22 \mathrm{~d}$, which equals $5.2 \mathrm{~J} \mathrm{~d}^{-1}$. The model predicted that females potentially obtain $10 \mathrm{~J} \mathrm{~d}^{-1}$ more than males as a result of their DVM, which more than meets the extra demand of egg production. This means that, under these conditions, females can reproduce actively without sacrificing somatic growth, which explains why there is little difference between the sizes of males and females throughout their life histories. The summer 1996 studyperiod coincided with a phytoplankton bloom (Lass et al. 2001), and so represents maximal energetic intake. Any surplus would presumably be stored to maintain reproductive output during periods when food is less abundant (Cuzin-Roudy et al. 1999). Such a strategy may also be common to Euphausia superba, where female energetic intake exceeds that of males during the summer (Clark \& Morris 1983).

\section{Influence of life-cycle strategies}

The model was not successful at predicting the sex ratio of the population through the winter period. Whereas the ratio of males-to-females was predicted to increase, reaching an ultimate level of $4: 1$, observations showed that the ratio actually decreased because the number of males in the population had declined relative to the number of females. This indicates that modelling mortality purely as a function of predation rate was not applicable during the winter period, and that other factors must have had an influence. 
Resources are short during the winter, and many plankton endure the period either as a resting egg or in a state of diapause. Krill remain active and must rely on lipid reserves to supplement the decreased levels of energy intake (Falk-Peterson et al. 2000). Mortality from starvation results when these reserves are not sufficient. Mature female northern krill can have a total lipid content twice as high as males, mostly due to lipid accumulation in the ovary, the fat body and the haemolymph (Cuzin-Roudy et al. 1999). The majority of lipids used in reproduction are energy-rich tryglycerides, dominated by polyunsaturated fatty acid (PUFA) chains. The PUFAs were not abundant in males or females in the non-reproductive season (Cuzin-Roudy et al. 1999). At the end of the reproductive season, lipids that have been allocated to developing eggs can be reabsorbed and used as an energy supplement (Cuzin-Roudy \& Amsler 1991). It seems likely, therefore, that females have greater energy reserves than males, and are less likely to starve during the winter. This effect was observed in Euphausia superba, where a swarm caught towards the end of the productive season showed a higher mortality rate in males than in females when incubated (Virtue et al. 1996). Tracking the decline of lipids in the male and female fractions over winter will be a good test of the hypothesis.

I found that smaller individuals went closer to the surface at night than larger individuals. However, the vertical migration of the very largest size class was an exception to this rule. Both the largest males and females, which were 2 (and possibly 3 ) yr olds, performed one of the riskiest DVMs by venturing as close to the surface at night as the smallest individuals. The fact that this phenomenon occurred in both sexes indicates that it might be age rather than sex that influences the level of risk undertaken at this stage of the life cycle. The occurrence of surface swarms in this (Nicol 1984) and other euphausiid species (Euphausia pacifica, Nakamura 1992; E. superba, Marr 1962; Thysanoessa inermis, Hanamura et al. 1989; T. raschii, Timofeyev 1994) is another example of where older individuals spend increasing amounts of time in the upper layers. The behaviour becomes explicable when considered in terms of life-time reproductive success (Mangel \& Clark 1988). During the first year of adulthood, the level of acceptable predation risk is determined by both present and future reproductive output. Greater risks in the near future may have immediate rewards with respect to the energy that can be invested in the present spawn or copulation, but also jeopardizes the chance of surviving to reproduce in the future. Towards the end of the life cycle, the number of expected future reproductions is low, and there is higher fitness in making the immediate spawn or cop- ulation successful through taking greater risks. Going to the surface allows maximum intake of food and, even though the risk is high, animals towards the end of their life cycle have less to lose.

I have shown that the different costs of reproduction could be influential in determining the respective DVM profiles of male and female krill. During a typical summer situation, the food intake resulting from the DVM profile of females more than met the demands for maximal reproductive output. The storage of surplus energy in the form of lipids is likely to occur during such times, to maintain reproductive output when resources decline. Alonzo \& Mangel (2001) suggested that krill could adopt shrinkage as a strategy to minimise predation risk, but this does not appear to be the case in Clyde Sea krill, given that females did not differ greatly in size to males, despite the respective differences in energetic demand. The increasing male-to-female ratio through the season that was identified in Clyde Sea krill is not a universal phenomenon in euphausiid populations, but this does not mean that females in other populations are not satisfying the same constraint of achieving a greater energetic intake than males. Depending on the environment, larger rates of ingestion can be obtained through subtle changes in DVM that incur little increased risk in the way of predation. Nevertheless, if and when the need arises, female Meganyctiphanes norvegica seem prepared to undertake greater risks to improve reproductive output.

Acknowledgements. I would like to thank J. B. L. Matthews, R. Saunders and T. Jarvis for their help with field sampling and the processing of samples, S. Emsley, who carried out a part of the ADCP post-processing, and P. Fretwell, who drafted the map of the sampling area. The work carried out in 1996 and 1997 was done on board RV 'Heincke' as part of the PEP project (EU-MAST III: MAS3-CT95-0013) and I am grateful to the crew and the PEP team members, especially $F$. Buchholz (project leader) and J. Cuzin-Roudy, for their assistance. I am indebted to the crew of RV 'Calanus' who were always helpful during the 1999 to 2000 campaigns, and also to C. Griffiths and M. Inall, who ably managed the mooring operations. Thanks also to the Marshalls for the use of their roof to site the LICOR sensor. J. B. L. Matthews, A. Atkinson and A. Hirst provided valuable constructive criticism to improve this manuscript. The 1999/2000 sampling campaigns were funded by a NERC MSTB fellowship (GST/59818MS). This paper is dedicated to the memory of Francis Lovie, a fine fisherman.

\section{LITERATURE CITED}

Alonzo SH, Mangel M (2001) Survival strategies and growth of krill: avoiding predators in space and time. Mar Ecol Prog Ser 209:203-217

Andersen V, Nival P (1991) A model of the diel vertical migration of zooplankton based on euphausiids. J Mar Res 49: 153-175

Boucher J, Ibanez F, Prieur L (1987) Daily and seasonal varia- 
tions in the spatial distribution of zooplankton populations in relation to the physical structure in the Ligurian Sea Front. J Mar Res 45:133-173

Boysen E, Buchholz F (1984) Meganyctiphanes norvegica in the Kattegat. Mar Biol 79:195-207

Clarke A, Morris DJ (1983) Towards an energy budget for krill: the physiology and biochemistry of Euphausia superba Dana. Polar Biol 2:69-86

Cummins KW, Wuycheck JC (1971) Caloric equivalents for investigations in ecological energetics. Mitt Int Ver Limnol 18:1-158

Cuzin-Roudy J (2000) Seasonal reproduction, multiple spawning, and fecundity in northern krill, Meganyctiphanes norvegica, and Antarctic krill, Euphausia superba. Can J Fish Aquat Sci 57:6-15

Cuzin-Roudy J, Amsler MO (1991) Ovarian development and sexual maturity staging in Antarctic krill, Euphausia superba Dana (Euphausiacea). J Crustac Biol 11:236-249

Cuzin-Roudy J, Buchholz F (1999) Ovarian development and spawning in relation to the moult cycle in Northern krill Meganyctiphanes norvegica (Crustacea: Euphausiacea), along a climatic gradient. Mar Biol 133:267-281

Cuzin-Roudy J, Albessard E, Virtue P, Mayzaud P (1999) The scheduling of spawning with the moult cycle in Northern krill (Crustacea: Euphausiacea): a strategy for allocating lipids to reproduction. Inv Reprod Dev 36:163-170

De Robertis A (2002) Size-dependent visual predation risk and the timing of vertical migration: an optimization model. Limnol Oceanogr 47:925-933

Falk-Petersen S, Hagen W, Kattner G, Clarke A, Sargent JR (2000) Lipids, trophic relationships, and biodiversity in Arctic and Antarctic krill. Can J Fish Aquat Sci 57: 178-191

Flagg CN, Smith SL (1989) On the use of the acoustic Doppler current profiler to measure zooplankton abundance. Deep-Sea Res 36:455-474

Giske J, Aksnes DL, Fiksen O (1994) Visual predators, environmental variables and zooplankton mortality risk. Vie Milieu 44:1-9

Greene CH, Wiebe PH, McClatchie S, Stanton TK (1991) Acoustic estimation of Antarctic krill. Nature 349:110

Hanamura Y, Kotori M, Hamaoka S (1989) Daytime surface swarms of the euphausiid Thysanoessa inermis off the west coast of Hokkaido, northern Japan. Mar Biol 102:369-376

Houston AI, McNamara JM, Hutchinson JMC (1993) General results concerning the trade-off between gaining energy and avoiding predation. Phil Trans R Soc Lond 341:375-397

Labat JP, Cuzin-Roudy J (1999) Population dynamics of the krill Meganyctiphanes norvegica (Sars) (Crustacea: Euphausiacea) in the Ligurian Sea (N-W Mediterranean Sea). Size structure, growth and mortality modeling. J Plankton Res 18:2295-2312

Lass S, Tarling GA, Virtue P, Matthews JBL, Mayzaud P, Buchholz F (2001) On the food of northern krill (Meganyctiphanes norvegica) in relation to its vertical distribution. Mar Ecol Prog Ser 214:177-200

MacDonald PDM, Green PEJ (1988) User's guide to program MIX: an interactive program for fitting mixtures of distributions. Icthus Data Systems, Hamilton, ON

Makarov RR, Denys CJ (1981) Stages of sexual maturity of Euphausia superba. BIOMASS Handbook Series 11. Scientific Committee on Antarctic Research, Cambridge

Mangel M, Clark CW (1988) Dynamic modelling in behavioral ecology. Princeton Univesity Press, Princeton, NJ

Marr JWS (1962) The natural history and geography of the Antarctic krill (Euphausia superba Dana). Disc Rep 32: 33-464

Matthews JBL, Buchholz F, Saborowski R, Tarling GA, Dallot
S, Labat JP (1999) On the physical oceanography of the Kattegat and Clyde Sea Area, as background to ecophysiological studies of the planktonic crustacean, Meganyctiphanes norvegica. Helgol Wiss Meeresunters 53:70-84

Mauchline J (1960) The biology of the euphausiid crustacean, Meganyctiphanes norvegica Sars. Proc R Soc Edinb B 67 : $141-179$

Mauchline J, Fisher LR (1969) The biology of euphausiids. Adv Mar Biol 7:1-454

Nakamura T (1992) Recent aspect of krill fishing grounds off Joban-Kashima area in relation to warming tendency. Bull Jpn Soc Fish Oceanogr 56:155-157 (in Japanese)

Nicol S (1984) Population structure of daytime surface swarms of the euphausiid Meganyctiphanes norvegica in the Bay of Fundy. Mar Ecol Prog Ser 18:241-251

Postel L, Fock H, Hagen W (2000) Biomass and abundance In: Harris RP, Wiebe PH, Lenz PH, Skjoldal HR, Huntley M (eds) Zooplankton methodology manual. Academic Press, San Diego, CA, p 83-192

Prus T (1975) Measurements of calorific value using Phillipson microbomb calorimeter. In: Grodzinski W, Klekowski RZ (eds) Methods for ecological bioenergetics. Blackwell Scientific Publications, Oxford, p 160-199

Riley GA (1956) Oceanography of the Long Island Sound 1952-1954 II Physical oceanography. Bull Bingham Oceanogr Collect 15:15-46

Rippeth TP, Midgely RP, Simpson JH (1995) The seasonal cycle of stratification in a Scottish fjord. In: Skjoldal HR, Hopkins C, Erikstad KE, Leinaas HP (eds) Ecology of fjords and coastal waters. Elsevier Science, Amsterdam p 85-92

Saborowski R, Brohl S, Tarling GA, Buchholz F (2002) Metabolic properties of northern krill, Meganyctiphanes norvegica, from different climatic zones. I. Respiration and excretion. Mar Biol 140:547-556

Tarling GA, Cuzin-Roudy J (2003) Evidence of synchronisation in the moulting activity of northern krill and its impact on recruitment. Limnol Oceanogr 48:2020-2033

Tarling GA, Buchholz F, Matthews JBL (1999a) The effect of a lunar eclipse on the vertical migration of Meganyctiphanes norvegica (Crustacea: Euphausiacea) in the Ligurian Sea. J Plankton Res 21:1475-1488

Tarling GA, Cuzin-Roudy J, Buchholz F (1999b) Vertical migration behaviour in the northern krill Meganyctiphanes norvegica is influenced by moult and reproductive processes. Mar Ecol Prog Ser 190:253-262

Tarling GA, Matthews JBL, Burrows M, Saborowski R, Buchholz F, Bedo A, Mayzuad P (2000) An optimisation model of the diel vertical migration of .Northern krill. (Meganyctiphanes norvegica) in the Clyde Sea and Kattegat. Can J Fish Aquat Sci 57 (Suppl 3):38-50

Tarling GA, Jarvis T, Emsley SM, Matthews JBL (2002) Midnight sinking behaviour of Calanus finmarchicus: a response to satiation or krill predation. Mar Ecol Prog Ser 240:183-194

Timofeyev SF (1994) Population structure of summer aggregations of the euphausiid Thysanoessa raschii (M Sars) in the southern part of the Barents Sea. Oceanology 33: 785-789

Virtue P, Nichols PD, Nicol S, Hosie G (1996) Reproductive trade-off in male Antarctic krill. Mar Biol 126:521-527

Watkins JL, Murray AWA (1998) Layers of Antarctic krill, Euphausia superba: are they just long krill swarms? Mar Biol 131:237-247

Wiebe PH, Morton AW, Bradley AM, Backus RH, Craddock JE, Barber V, Cowles TJ, Flierl GR (1985) New developments in the MOCNESS, an apparatus for sampling zooplankton and micronekton. Mar Biol 87:313-323 